\title{
Affective Profiling to Determine Propensity for Empowerment or Disempowerment: Protective Attributes or Afflictive Proclivities in Depressive States and Well-Being
}

Trevor Archer ${ }^{1,2^{*}}$ and Danilo Garcia ${ }^{1-4}$

${ }^{1}$ Department of Psychology, University of Gothenburg, Gothenburg, Sweden

${ }^{2}$ Network for Empowerment and Well-Being, Sweden

${ }^{3}$ Blekinge Center of Competence, Blekinge County Council, Karlskrona, Sweden

${ }^{4}$ Centre for Ethics Law and Mental Health (CELAM), University of Gothenburg, Gothenburg, Sweden

\section{Editorial}

A plethora of studies focusing on affective personality attributes, positive affect (PA) and negative affect (NA), have measured ubiquitously self-reports of the Positive Affect and Negative Affect Schedule (PANAS), forming the basis of prevailing notions regarding health and well-being over different ethnical populations, gender and clinical and healthy volunteer populations [1-27]. Invariably, these studies have measured participants' self-reported feelings of enthusiasm, activity, feelings of duty, control, strong, proud (i.e., PA) linking them to wellbeing, proneness to frequent exercise and agentic, cooperative, and spiritual behaviors (e.g., self-acceptance, goal-orientations, empathy, helpfulness, seeking support in faith, meaningfulness). In contrast, feelings such as anger, guilt, shame contempt, and distress (i.e., NA) are associated with anxiety, depressiveness, ill-being, rumination, inaction (e.g., low exercise frequency and passive leisure activities such as watching TV) and health problems [28-32]. These studies show that PA and NA ought to be viewed as separate entities [33], despite the temptation to view them as opposite poles on a continuum.

On the basis of the above and other studies [34-36], the notion of the "affective profiles" was coined by proposing four possible combinations using individuals' experiences of high/low positive/negative affect: (1) high positive affect and low negative affect (i.e., the "self-fulfilling" profile), (2) low positive affect and low negative affect (i.e., the "low affective" profile), (3) high positive affect and high negative affect (i.e., the "high affective" profile), and (4) low positive affect and high negative affect (i.e., the "self-destructive" profile). See Figure 1 for a study [37,38] showing the distribution of profiles across 2,225 USresidents. This model of the affective system is of special importance because of discerned inconsistencies in cases wherein individuals express similar levels of affectivity in one dimension (e.g. low-low) yet express different levels in the other dimension (e.g., low-high) [38]. For example, as in the case where those expressing a "low affective" profile (i.e. low PA, Low NA) report greater life satisfaction in relation to the "self-destructive* profile (low PA, high NA), implying that the greater the extent of life satisfaction, the greater the reduction in NA expression when PA expression is low. Notwithstanding the robust aspects of these profiles, these self-reported evaluations of NA appear to vacillate according to the variations of testing condition: [39] found that the more individuals made self-evaluations of NA, the less pronounced (sometimes nonexistent) were the associations between everyday experiences of NA and a range of indicators for poorer psychosocial functioning (emotional health problems, social integration, etc.) and physical health (number health complaints, hand grip strength, momentary physical well-being, etc.). In essence, affective profiling can be used to determine peoples' propensity for empowerment or disempowerment, subject, at least partially, to the "whims-of-fate".

Personal empowerment is cocooned in the notion of a person- environment composition wherein 'person' brings a genetic predisposition and 'environment' implies those social, psychological and physical forces impinging post conception and through fetal, infancy, childhood and adolescence phases in an epigenetic orchestration of development. It is defined as the current habitus of multidimensional processes of reciprocally-determining interactions associated with the attainment of an individual's self-awareness, control and disposition of his/her life and well-being [40,41]. Disempowerment on the other hand, involves ill-being expressed as multidimensional processes of reciprocally-determining interactions associated with distress in an adverse epigenetic spiral of fear, unfulfillment, defeat, disappointment, dissatisfaction, frustration, disillusionment, setbacks, sadness, regret and adversity. Well-being, whether subjective or psychological, are often seen as notions of individuals' sense of life satisfaction in relation to an ideal situation in combination with their personal experiences of PA and NA, but also as her/his ability to create positive relations with others, self-acceptance, sense of control of one's environment, selfdetermination, purpose in life and personal growth [42]. Certainly, well-being involves a state of contentment in happiness, but also in health and prosperity [43-47]. Seeing well-being in this way, leads to the importance of ternary structures, such as, body (a): vitality and versatility, embodying physical fitness, energy, positive emotions, plasticity, resilience, etc; mind:(b) life satisfaction, self-determination, positive thinking etc, and soul (c): spiritual aptitude involving selftranscendence values and virtues such as hope, patience, trust, justice, moderation, honor, courage, wisdom, patience, love and faith $[48,49]$.

The disempowering influence of NA and its associations with clinical depression and anxiety have been established [50,51]. In a study of male war veterans, telomere length, which is linked to health and longevity [52] correlated positively with PA but negatively with early trauma and global psychopathological severity [53]. Nevertheless, the developmental trajectory of PA and NA is not always straightforward: thus, in a sub-longitudinal study of adolescents' development of social and executive functioning [54], it was observed that behavioral

*Corresponding author: Archer T, Department of Psychology, University of Gothenburg, Box 500, S-405 30 Gothenburg, Sweden, Tel: +46 31 7864694; E-mail: trevor.archer@psy.gu.se

Received: December 07, 2015; Accepted: December 07, 2015; Published: December 15, 2015

Citation: Archer T, Garcia D (2015) Affective Profiling to Determine Propensity for Empowerment or Disempowerment: Protective Attributes or Afflictive Proclivities in Depressive States and Well-Being. Clin Exp Psychol 2: e102. doi:10.4172/24712701.1000e102

Copyright: ( 2015 Archer T, et al. This is an open-access article distributed under the terms of the Creative Commons Attribution License, which permits unrestricted use, distribution, and reproduction in any medium, provided the original author and source are credited. 


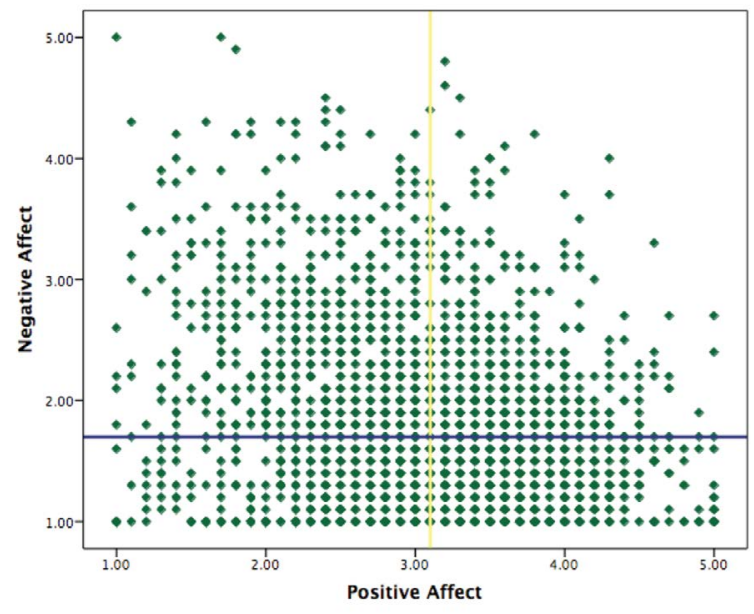

Figure 1: Distribution of positive and negative affect in a sample of 2,225 USresidents (Reprinted with permission from Garcia et al., 2015b). The vertical yellow line marks the median for positive affect (3.10) and the horizontal blue line marks the median for negative affect (1.70).

inhibition, rule detection, strategy generation and planning executive functions and emotion recognition with dynamic stimuli evolved over testing times (separated by 12-16 month intervals). Self-reported empathy and emotion recognition functions using visual static and auditory stimuli were stable by the age of 17 years whereas concept formation declined between time points. Nevertheless, although PA was increased and NA was reduced from 17 to 19 years of age these effects did not reach significance [55] have shown that adaptive coping behavior was correlated positively with PA and social support whereas maladaptive coping behavior was correlated positively with NA, and inversely related to PA and social support, implying that interventions that harness positive resources, such as social support and positive mood, should facilitate adaptive coping. Physical exercise, a strong agent of empowerment associated with individuals whose affect profiles are invariably positive, and generates a wide variety of physical and psychological health benefits [56,57]; both compliance and propensity for exercise are predicted by PA.

The pain-depression link implies shared neurobiology, precipitating environmental factors and cognitive influences that may be exemplified through recourse to aspects of ill-being present ubiquitously in fibromyalgia [58]. The notion of "Affect Balance" which estimates the relative levels of NA and PA has been introduced to capture emotional functioning levels more effectively than than NA or PA alone $[59,60]$, showed that depressive patients (low PA, high NA comparable to "Selfdestructives") and reactive patients (high PA, high NA comparable to "High affectives") affect balance styles were predominant in fibromyalgia patients and related to poor functioning and psychiatric comorbidity [59]. In contrast, a "Healthy affect balance" style (high PA, low NA comparable to "Self-fulfilling") was associated with superior physical and psychological symptom profiles in fibromyalgia patients [60]. From a sample of 858 fibromyalgic patients who responded to several questionaires [61] argued that (i) PA and NA would be associated with fibromyalgia symptom burden; (ii) resilience would be associated with PA and NA; (iii) resilience would be associated with fibromyalgia symptom burden; and (iv) the connection between resilience and fibromyalgia symptom burden would be mediated by both PA and NA. Using mediation modelling, they showed that resilience exerted a direct effect upon fibromyalgia symptom burden (iii), and that there were indirect effects of resilience upon fibromyalgia symptom burden through PA and NA (i, ii and iv), thereby concluding that efforts to improve affect through resiliency training offered a avenue for alleviation of the fibromyalgia symptom burden. If one assumes the the fibrimyalgic condition presents a position of disempowerment, the evidence here implies that increments of the PA profiles or "Healthy affect balance", i.e. developing a "Self-fulfilling" profile, render patients more resilient and therewith more empowered (Archer \& Garcia, submitted).

Beyond the intrinsic value of experiencing 'more happiness', PA confers upon individuals' welfare a marked degree of health and well-being [62-66] and is linked to healthy lifestyles [67,68]. Several physiological domains, including the neuroendocrine, autonomic and neuroimmune systems, as well as survival, are activated by PA and associated attributes [69-75]. PA and its biological correlates appears to exert a distinctive influence upon psychobiological processes that are independent of NA. Applying fibrinogen and C reactive protein as indexes of systemic inflammation, have found an inverse relationship between PA and fibrinogen, as well as an inverse association between $\mathrm{PA}$ and $\mathrm{C}$ reactive protein. It has been observed that in chronic obstructive pulmonary disease that both self-management capability and quality-of-life were mediated through the empowering effects of PA. In young adults presenting chronic pain PA was associated with efficacy of 'work-goal' schedules and 'work-goal' striving. Certainly, in the context of health and well-being, the appreciation of PA may not be overestimated since patients expressing high levels of PA reported fewer symptoms linked with NA, such as anxiety and despondency, and they preserved their habitual relationships and social roles to a greater extent [76]. The authors imply that PA offers a basic disposition that to bolster cancer patients' efforts to adapt suitably to severe illness, through compliance with the prescribed medical treatment and by applying cognitive strategies that enable them to cope with the concurrent and prospective challenges of illness. In a study performed upon Chinese nurses, involving the relationships between perceived structural empowerment (i.e. structures within the organization rather than an individual's attributes), psychological empowerment, burnout and "intent-to-stay" [77] showed that structural empowerment and psychological empowerment induced marked positive effects on "intent-to-stay" and negative effects on burnout which induced negative effects on "intent-to-stay" thereby illustrating the protective effects of conditions facilitating empowerment and the afflictive proclivity of disempowerment.

Taken together, there is a profusion of evidence from health and well-being reviews, psychobiological research, occupational and behavioral medicine clinical studies supporting the contention that PA might stand for empowerment, while NA stands for disempowerment. Most importantly, from a person-centered framework these two affectivity dimensions within the individual can be seen as interwoven components with whole-system properties [78]. The outlook of the individual as a whole-system unit is then best studied by analyzing patterns of information [79]. Although at a theoretical level there is a myriad of probable patterns of combinations of peoples' levels of positive and negative affect, if viewed at a global level, there should be a small number of more frequently observed patterns or "common affective types" [80-82], who explain nonlinear dynamics in complex adaptive systems).

\section{References}

1. Adriansson L, Ancok D, Ramdhani N, Archer T (2014) Cultural influences 
upon health, affect, self-esteem and impulsiveness: An Indonesian-Swedish comparison. Int J Res Stud Psychol.

2. Andersson-Arntén AC, Jansson B, Archer T (2008) Influence of affective personality type and gender upon coping behavior, mood and stress. Individ Diff Res 6: 139-168.

3. Archer T, Adrianson L, Plancak A, Karlsson E (2007) Influence of affective personality on cognition-mediated emotional processing. Eur J Psychiatr 21 $248-262$

4. Archer T, Adolfsson B, Karlsson E (2008) Affective personality as cognitiveemotional presymptoms profiles regulatory for self-reported health predispositions. Neurotoxicity Res 14: 1-25.

5. Garcia D (2011a) Adolescents' happiness: the role of the affective temperament model on memory and apprehension of events, subjective well-being, and psychological well-being. Doctoral Dissertation, University of Gothenburg, Department of Psychology.

6. Garcia D (2011b) The affective temperaments: differences between adolescents in the Big Five Model and Cloninger's Psychobiological Model of Personality. J Happiness Studies.

7. Garcia D (2012a) Interpretation and recognition for words in a short story (IRWSS) [Databas record]. Retrieved from the American Psychological Association's PsycTESTSTM

8. Garcia D (2012b) The affective temperaments and self-acceptance: adolescents' life satisfaction and psychological well-being. In M. Vassar (Ed.), The Psychology of Life Satisfaction (pp.) New York: Nova Science Publishers.

9. Garcia D, Archer T (2012) Adolescent life satisfaction and well-being. J Altern Med Res 4: 271-279.

10. Garcia D, Rosenberg P, Erlandsson A, Siddiqui A (2010) On Lions and Adolescents: Affective Temperaments and the Influence of Negative Stimuli on Memory. Journal of Happiness Studies 11: 477-495.

11. Garcia D, Moradi S (2012) Adolescents' Temperament and Character: A Longitudinal Study on Happiness. Journal of Happiness Studies 13: 931-946.

12. Garcia D, Ghiabi B, Moradi S, Siddiqui A, Archer T (2012a) The happy personality: a tale of two philosophies. In N. Gotsiridze-Columbus Vassar (Ed.), Psychology of Personality (pp.) New York: Nova Science Publishers.

13. Garcia D, Kerekes N, Andersson Arntén A-C, Archer T (2012b) Temperament character, and adolescents' depressive symptoms: focusing on affect. Depress Res Treat.

14. Garcia D, Archer T, Moradi S, Andersson-Arntén A-C (2012) Exercise Frequency, High Activation Positive Affectivity, and Psychological Well-Being: Beyond Age, Gender, and Occupation. Psychology. 3: 328-336.

15. Garcia D, Erlandsson A (2011) The relationship between personality and subjective well-being: different association patterns when measuring the affective component in frequency and intensity. J Happiness Stud 12: 10231034.

16. Garcia D, Siddiqui A (2009a) Adolescents' affective temperaments: life satisfaction, interpretation and memory of events. J Positive Psychol 4: 155167.

17. Garcia D, Siddiqui A(2009b) Adolescents' psychological well-being and memory for life events: influences of life satisfaction with respect to temperamental dispositions. J Happiness Stud 10: 387-503

18. Karlsson E, Archer T (2007) Relationship between personality characteristics and affect: gender and affective personality. Individ Diff Res 5: 44-58.

19. Lindahl M, Archer T (2013) Depressive expression and anti-depressive protection in adolescence: stress, positive affect, motivation and self-efficacy. Psychology 4: 495-505.

20. Nima AA, Rosenberg P, Archer T, Garcia D (2013) Anxiety, affect, self-esteem, and stress: mediation and moderation effects on depression. PLoS One 8: e73265.

21. Palomo T, Kostrzewa RM, Beninger RJ, Archer T (2007) Treatment consideration and manifest complexity in comorbid neuropsychiatric disorders. Neurotoxicity Res 12: 43-60.

22. Palomo T, Beninger RJ, Kostrzewa RM, Archer T (2008a) Focusing on symptoms rather than diagnoses in brain dysfunction: conscious and nonconscious expression in impulsiveness and decision-making. Neurotoxicity
Res 14: 1-20.

23. Palomo T, Beninger RJ, Kostrzewa RM, Archer T (2008b) Affective status in relation to impulsiveness, motor and motivational symptoms: personality , development and physical exercise. Neurotoxicity Res.14: 151-168.

24. Schütz E, Sailer U, Nima AA, Rosenberg P, Andersson-Arntén AC et al. (2013a) The affective profiles in the USA: happiness, depression, life satisfaction, and happiness-improving strategies. PeerJ 1:e156.

25. Schütz E, Archer T, Garcia D (2013b) Character profiles and adolescents' selfreported affect. Pers Individ Diff 54: 841-844

26. Zöller M, Archer T (2009) Predicting stress in male and female psychiatric patients and healthy volunteers. Soc Behav Pers. 37: 1081-1094.

27. Zöller M, Karlsson E, Archer T (2009) Self-rated affect among adults presenting psychiatric diagnosis. Individ Diff Res 7: 14-28.

28. Watson D, Clark L (1988) Positive and negative affectivity and the relation to anxiety and depressive disorders. J Abnorm Psychol 97: 346-353.

29. Watson D, Tellegen A (1985) Toward a consensual structure of mood Psychol Bull. 98: 219-235.

30. Watson D, Pennebaker JW, Folger (1986) Beyond negative affectivity: measuring stress and satisfaction in the workplace. J Organ Behav Manag 8: 141-157.

31. Watson D, Clark LA, Carey G (1988) Positive and negative affectivity and thei relation to anxiety and depressive disorders. J Abnorm Psychol 97: 346-353.

32. Watson D, Clark L, Tellegen A (1988b) Development and validation of brief measures of positive and negative affect: the s scales. J Person Soc Psychol 54: 1063-1070.

33. MacLeod AK, Moore R (2000) Positive thinking revisited: positive cognitions, well-being and mental health. Clin Psychol Psychother 7, 1-10.

34. Garcia D, Lindskär, E, Archer T (2015) Thinking Outside the Box About Indicators of Well-Being: Agency, Communion, and Positivity. International Journal of Happiness and Development 2: 182-191.

35. Garcia D, MacDonald S, Archer T (2015b) Two different approaches to the affective profiles model: median splits (variable-oriented) and cluster analysis (person-oriented). PeerJ 3: e1380.

36. Schütz E, Garcia D, Archer T (2014) Affective state, stress, and Type A-personality as a function of gender and affective profiles. Int $\mathrm{J}$ Res Stud Psychol.

37. Garcia D, Lindskär E, Archer T (2014) To schedule or not to schedule? Agentic and cooperative teams at call centers. Front Psychol 5: 999.

38. Garcia D (2011c) Two models of Personality and Well-being among adolescents Pers Individ Diff 50: 1208-1212.

39. Luong G, Wrzus C, Wagner GG, Riediger M (2015) When Bad Moods May Not Be So Bad: Valuing Negative Affect Is Associated With Weakened AffectHealth Links.

40. Garcia D, Archer T (2014) Positive affect and age as predictors of exercise compliance. PeerJ 2: e694

41. Garcia D, Jimmefors A, Mousavi F, Adrianson L, Rosenberg P, et al. (2015) Selfregulatory Mode (Locomotion and Assessment), Well-Being (Subjective and Psychological), and exercise behavior (Frequency and Intensity) in Relation to High School Pupils' Academic Achievement. PeerJ 3: e847.

42. Jimmefors A, Garcia D, Rosenberg P, Mousavi F, Adrianson L et al. (2014) Locomotion (Empowering) and Assessment (Disempowering) Self-regulatory Dimensions as a Function of Affective Profile in High School Students. International Journal of School and Cognitive Psychology 2: 103.

43. Cloninger CR (2004) Feeling good: the science of well-being. New York: Oxford University Press.

44. Cloninger CR (2005) Book review of Peterson and Seligman's character and human virtues. American Journal of Psychiatry 162:820-821.

45. Cloninger CR1 (2008) On well-being: current research trends and future directions. Mens Sana Monogr 6: 3-9.

46. Cloninger CR (2012) Science of well-being: how to be healthy, happy, \& fulfilled in the face of current world challenges. Gothenburg: Lecture conducted from the University of Gothenburg. 
Citation: Archer T, Garcia D (2015) Affective Profiling to Determine Propensity for Empowerment or Disempowerment: Protective Attributes or Afflictive Proclivities in Depressive States and Well-Being. Clin Exp Psychol 2: e102. doi:10.4172/2471-2701.1000e102

47. Cloninger CR (2013) What makes people healthy, happy, and fulfilled in the face of current world challenges? Mens Sana Monographs 11: 16-24.

48. Moreira PA, Cloninger CR, Dinis L, Sá L, Oliveira JT, et al. (2015) Personality and well-being in adolescents. Front Psychol 5: 1494.

49. Falhgren E, Nima AA, Archer T, Garcia D (2015) Person-Centered Osteopathic Practice: Patients' Personality (Body, Mind, and Soul) and Health (III-Being and Well-Being). PeerJ 3: e1349.

50. Buz J, Pérez-Arechaederra D, Fernández-Pulido R, Urchaga D (2015) Factorial Structure and Measurement Invariance of the PANAS in Spanish Older Adults. Span J Psychol 18:E3.

51. Carvalho HW, Andreoli SB, Lara DR, Patrick CJ, Quintana MI, et al. (2014) The joint structure of major depression, anxiety disorders, and trait negative affect. Rev Bras Psiquiatr 36: 285-92.

52. Archer T (2015) Exercise influences in depressive disorders: symptoms, biomarkers and telomeres. Clinical Depression, 1: e101.

53. Bersani FS, Lindqvist D, Mellon SH, Epel ES, Yehuda R, et al. (2015) Association of dimensional psychological health measures with telomere length in male war veterans. J Affect Disord 190:537-542.

54. Taylor SJ, Barker LA, Heavey L, McHale S (2015) The longitudinal developmen of social and executive functions in late adolescence and early adulthood. Front Behav Neurosci 9:252.

55. Webb Hooper M, Baker EA, McNutt MD (2013) Associations between coping affect, and social support among low-income African American smokers. Addict Behav 38: 2736-40.

56. Archer T, Garcia D (2014a) Physical exercise influences academic performance and well-being in children and adolescents. Int J School Cogn Psychol.

57. Archer T, Garcia D Empowerment Components that Endower Resilience through Positive Affect: Character (Hope and Love), Intrinsic Motivation (Agency), and Locomotion (Goal-pathway). Under editorial evaluation.

58. Goesling J, Clauw DJ, Hassett AL (2013) Pain and depression: an integrative review of neurobiological and psychological factors. Curr Psychiatry Rep 15 421

59. Hassett AL, Simonelli LE, Radvanski DC, Buyske S, Savage SV, et al. (2008) The relationship between affect balance style and clinical outcomes in fibromyalgia. Arthritis Rheum 59: 833-840.

60. Toussaint LL, Vincent A, McAllister SJ, Oh TH, Hassett AL (2014) A Comparison of Fibromyalgia Symptoms in Patients with Healthy versus Depressive, Low and Reactive Affect Balance Styles. Scand J Pain 5: 161-166.

61. McAllister SJ, Vincent A, Hassett AL, Whipple MO, Oh TH, et al. (2015) Psychological Resilience, Affective Mechanisms and Symptom Burden in a Tertiary-care Sample of Patients with Fibromyalgia. Stress Health 31: 299-305.

62. Chida Y, Steptoe A (2008) Positive psychological well-being and mortality: a quantitative review of prospective observational studies. Psychosom Med 70: 741-756.

63. Chida Y, Steptoe A (2009) Cortisol awakening response and psychosocia factors: a systematic review and meta-analysis. Biol Psychol 80: 265-278.

64. Pressman SD, Cohen S (2005) Does positive affect influence health? Psycho Bull 131: 925-971.

65. Taber JM, Klein WM, Ferrer RA, Kent EE, Harris PR (2015) Optimism and Spontaneous Self-affirmation are Associated with Lower Likelihood of Cognitive Impairment and Greater Positive Affect among Cancer Survivors. Ann Behav Med.
66. Grant N, Wardle J, Steptoe A (2009) The relationship between life satisfaction and health behavior: a cross-cultural analysis of young adults. Int J Behav Med 16: 259-68.

67. Sheinbaum T, Kwapil TR, Ballespí S, Mitjavila M, Chun CA, et al. (2015) Attachment style predicts affect, cognitive appraisals, and social functioning in daily life. Front Psychol 6: 296.

68. Bostock S, Hamer M, Wawrzyniak AJ, Mitchell ES, Steptoe A (2011) Positive emotional style and subjective, cardiovascular and cortisol responses to acute laboratory stress. Psychoneuroendocrinology 36: 1175-83.

69. Ong AD, Exner-Cortens D, Riffin C, Steptoe A, Zautra A, et al. (2013) Linking stable and dynamic features of positive affect to sleep. Ann Behav Med 46: $52-61$

70. Ronaldson A, Poole L, Kidd T, Leigh E, Jahangiri M, et al. (2014) Optimism measured pre-operatively is associated with reduced pain intensity and physical symptom reporting after coronary artery bypass graft surgery. J Psychosom Res 77: 278-82.

71. Roque L, Veríssimo M, Oliveira TF, Oliveira RF (2012) Attachment security and HPA axis reactivity to positive and challenging emotional situations in childmother dyads in naturalistic settings. Dev Psychobiol 54: 401-11.

72. Steptoe A, Wardle J (2011) Positive affect measured using ecological momentary assessment and survival in older men and women. Proc Natl Acad Sci U SA 108: 18244-8.

73. Valdimarsdottir HB, Bovbjerg DH (1997) Positive and negative mood: association with natural killer cell activity. Psychol Health 12: 319-327.

74. Zschucke E, Renneberg B, Dimeo F, Wüstenberg T, Ströhle A (2015) The stress-buffering effect of acute exercise: Evidence for HPA axis negative feedback. Psychoneuroendocrinology 51: 414-25.

75. Dockray S, Steptoe A (2010) Positive affect and psychobiological processes Neurosci Biobehav Rev 35: 69-75.

76. Steptoe A, O'Donnell K, Badrick E, Kumari M, Marmot M (2008) Neuroendocrine and inflammatory factors associated with positive affect in healthy men and women: the Whitehall II study. Am J Epidemiol 167: 96-102.

77. Mun CJ, Karoly P, Okun MA, Kim H, Tennen H (2015) Affect, work-goal schemas, and work-goal striving among adults with chronic pain: a multilevel structural equation analysis. J Behav Med.

78. Vittorio Caprara G, Castellani V, Alessandri G, Mazzuca F, La Torre M, et al (2015) Being positive despite illness: The contribution of positivity to the quality of life of cancer patients. Psychol Health 11:1-16.

79. Meng L, Liu Y, Liu H, Hu Y, Yang J, et al. (2015) Relationships among structura empowerment, psychological empowerment, intent to stay and burnout in nursing field in mainland China-based on a cross-sectional questionnaire research. Int J Nurs Pract 21: 303-12.

80. Bergman LR, Magnusson D (1997) A person-oriented approach in research on developmental psychopathology. Development and Psychopathology 9: 291319 .

81. Bergman LR, Wangby M (2014) The person-oriented approach: a short theoretical and practical guide. Eesti Haridusteaduste Ajakiri 2: 29-49.

82. Benzo RP, Abascal-Bolado B, Dulohery MM (2015) Self-management and quality of life in chronic obstructive pulmonary disease (COPD): The mediating effects of positive affect. Patient Educ Couns pii: S0738-3991: 30112-119. 